\title{
Ocular manifestation, eye protection, and COVID-19
}

\section{Rujittika Mungmungpuntipantip ${ }^{1}$ - Viroj Wiwanitkit ${ }^{2,3}$}

Received: 7 March 2020 / Revised: 19 March 2020 / Accepted: 25 March 2020 / Published online: 30 March 2020

(C) Springer-Verlag GmbH Germany, part of Springer Nature 2020

\section{Dear Editor,}

We found that the report on "Stepping up infection control measures in ophthalmology during the novel coronavirus outbreak: an experience from Hong Kong" is very interesting [1]. Lai et al. noted that "In order to minimise transmission of COVID-19, ophthalmologists should work closely with local infection control teams to implement infection control measures that are appropriate for their own clinical settings [1].” In fact, Li et al. pointed out the possibility of ocular manifestation in COVID-19 and the importance of eyewear [2]. We would like to share ideas and experience from Thailand, the second country in Southeast that the new infection-19 has been occurred for 3 months [3]. At present (March 6, 2020), there are accumulated 48 COVID-19 patients. From these 48 cases, the complete physical examination including the eye examination, which includes direct ophthalmoscopy and further corneal scraping in suspicious conjunctivitis case, to detect ocular manifestation was done in each case, and there is no report on ocular problem. Nevertheless, it should note that the ocular manifestation is usually overlooked by Thai practitioners. The local infection control guidelines provided by local medical professor team state for only fever and respiratory manifestation (local guideline by the Department of Medical Services, Ministry of Public Health is available online at https://www. dms.moph.go.th/backend//Content/Content_File/Practice guidelines/Attach/25630213145852PM_2019-nCoV_flow_ HosManage_Feb5.pdf). It is no doubt that the case with initial presentation of eye problem is easily missed. In addition, there has never recommendation for eyewear use in medical practice. Practitioner usually wears facemask and exposes eyes to the patient. Modification of the present infection control guidelines to include the eye protective device during medical practice is suggested. It is necessary to educate the practitioner for recognizing possible ocular manifestation of COVID-19.

\section{Compliance with ethical standards}

Conflict of interest The authors declare that they have no conflict of interest.

\section{References}

1. Lai THT, Tang EWH, Chau SKY, Fung KSC, Li KKW (2020) Stepping up infection control measures in ophthalmology during the novel coronavirus outbreak: an experience from Hong Kong. Graefes Arch Clin Exp Ophthalmol. https://doi.org/10.1007/ s00417-020-04641-8

2. Li JO, Lam DSC, Chen Y, Ting DSW (2020) Novel coronavirus disease 2019 (COVID-19): the importance of recognising possible early ocular manifestation and using protective eyewear. $\mathrm{Br} \mathrm{J}$ Ophthalmol 104(3):297-298

3. Yasri S, Wiwanitkit V (2019) Editorial: Wuhan coronavirus outbreak and imported case. Adv Trop Med Pub Health Int 9:1-2

Publisher's note Springer Nature remains neutral with regard to jurisdictional claims in published maps and institutional affiliations.

Rujittika Mungmungpuntipantip

rujittika@gmail.com

26 Medical Center, Bangkok, Thailand

DY Patil University, Pune, India

Hainan Medical University, Haikou, China 